EXTENDED REPORT

\title{
Immunohistochemistry of normal human knee synovium: a quantitative study
}

\author{
J A Singh, T Arayssi, P Duray, H R Schumacher
}

Ann Rheum Dis 2004;63:785-790. doi: 10.1136/ard.2003.013383

See end of article for authors' affiliations

.....................

Correspondence to: Dr Jasvinder A Singh, Minneapolis VA Medical Center $111 \mathrm{R}$, One Veteran's drive,

Minneapolis, MN 55417

USA; singh046@umn.edu

Accepted 21 October 2003

\begin{abstract}
Objective: To describe the immunohistochemical characteristics of knee synovium from normal healthy subjects.

Methods: 12 healthy subjects underwent needle biopsy of knee synovium. Using antibodies directed against CD3, CD4, CD8, L26, Kp-1, and HLA-DR, detailed quantitative immunohistochemical analysis of various cell subpopulations was undertaken.

Results: The mean (SD) age of the subjects was 37 (9) years (five male, seven female). All had a negative history for arthritis, no knee pain, and a totally normal joint examination except for the presence of retropatellar crepitus in five. For technical reasons staining for all immunohistochemical markers could not be achieved in all subjects. CD3+ T lymphocytes were seen in nine of 10 subjects, either diffusely or, more commonly, in perivascular areas. CD4+ cells were seen in synovium in three of seven subjects and CD8+ cells in six of eight subjects, in almost equal numbers (CD4:CD8, 1.1:1). L26+ B lymphocytes were not seen in any biopsy. Kp1+ macrophages were found in 10 of 10 subjects, predominantly in surface lining cells, and in small numbers in diffuse and perivascular locations. HLA-DR+ cells were seen in 10 of 10 subjects, predominantly in surface lining cells and diffusely, but a few were seen perivascularly.

Conclusions: Synovium from apparently normal subjects contained a wide range of different cell subpopulations but no B cells. The significance of these immune cells in normal synovium is unclear. A better understanding of their role in normal synovium may be important in analysing the transition to synovitis.
\end{abstract}

$\mathrm{T}$ e study of the synovium is fundamentally important in understanding the pathogenesis of inflammatory synovial diseases such as rheumatoid arthritis, spondyloarthropathies, and other causes of inflammatory synovitis. With the advent of new biological treatments for inflammatory synovitis, various studies have evaluated the effect of these on synovial pathology and cellular infiltrates identified by immunohistochemistry. Light and electron microscopic evaluation of the human synovium has been described in a few studies. ${ }^{1-7}$ However, cellular characteristics defined by immunohistochemistry of the synovium in normal subjects without any joint trauma and with normal laboratory and clinical findings have been reported only in one study that included four normal subjects. ${ }^{8}$ All other immunohistochemical studies used synovial samples obtained at the time of joint surgery for traumatic knee injury or limb amputation (for vascular disease or malignancy) or at necropsy, ${ }^{9-15}$ and thus did not include normal healthy subjects by definition. Our knowledge of immunohistochemical characteristics of normal healthy synovium is therefore very limited.

Histological and immunohistochemical studies of synovium from normal and traumatic joints have produced conflicting results. Histological studies of synovium from traumatic joints ${ }^{37}$ did not report the presence of any macrophages or lymphocytes, which are usually seen in inflammatory synovitis. Immunohistochemical studies of traumatic joints showed the presence of macrophages, ${ }^{15} 16$ HLA-DR positive cells, ${ }^{10}{ }^{12}{ }^{15-18} \mathrm{few}^{15}$ or no ${ }^{10}{ }^{14} \mathrm{~T}$ cells, and no B cells. ${ }^{10} 1415$ It is possible that some of the synovial cellular infiltration reported in these studies may have been secondary to the injury leading to the surgery. In the only study of four normal healthy subjects, immunohistochemical staining detected the presence of $\mathrm{T}$ lymphocytes (mainly perivascular), synovial lining HLA-DR positive cells, and only very occasional B cells. ${ }^{8}$ Haematoxylin and eosin staining of the same specimens, interestingly, did not detect any lymphocytes. ${ }^{8}$ Histological studies may not be sensitive enough to show the presence of lymphocytes with certainty.

The recent finding of the presence of bacterial DNA in joints of normal subjects ${ }^{19}$ raises a critical issue: do clinically normal joints perhaps have a wider spectrum of appearances and states than is often appreciated? While the only study of normal human synovium provides some insight into various resident synovial cell populations, the number of subjects in the study was small, ${ }^{8}$ though that study also undertook a qualitative analysis of cell subpopulations. Our aim in the present study was therefore to undertake a quantitative immunohistochemical study in a larger group of normal subjects. We wanted to test whether we could confirm the important observations made by Lindblad et $a l^{8}$ in their four subjects, as those findings may need emphasising. We describe here the varying populations of immune cells in the synovium of 12 healthy subjects.

\section{METHODS Subjects}

After approval from the ethics committee at National Institute of Arthritis and Musculoskeletal Diseases (NIAMS) and informed consent, normal subjects of over 18 years of age were enrolled in a protocol to study several aspects of the normal synovium. As criteria for entering in the study, all subjects had to be healthy, with no known medical illnesses, to be totally free of any knee or other joint symptoms, and to have no objective signs of arthritis. All subjects gave a full history and underwent a physical examination by an experienced rheumatologist (HRS) at the Clinical Center, NIAMS, National Institutes of Health, Bethesda, Maryland. They all had a battery of blood tests and standing $x$ rays of both knees. Subjects were excluded if they had a history of any chronic illness or were found to have an 
abnormality on examination other than mild retropatellar crepitus. Laboratory studies done included complete blood count, clotting studies, rheumatoid factor (RF), antinuclear antibody (ANA), erythrocyte sedimentation rate (ESR), $\mathrm{C}$ reactive protein, serum creatinine, liver function tests, hepatitis screen, and urinalysis. In addition, all had serological assays to screen for antibodies to salmonella, shigella, yersinia, campylobacter, Chlamydia trachomatis and Chlamydia pneumoniae, and parvovirus B19.

\section{Synovial biopsy}

Between 1995 and 1997, all subjects underwent blind synovial biopsy of one knee, with the use of a ParkerPearson (PP) needle as previously described..$^{21}$ The skin overlying the joint was prepared with benzylkonium, draped, and infiltrated with $1 \%$ lignocaine (lidocaine). An attempt was made to aspirate the joint to exclude the presence of an effusion before installation of lignocaine into the joint, and no fluid was obtained from any. The PP needle was inserted through a medial approach and up to 20 pieces of synovial tissue were removed through the cannula. Specimens were immediately placed in formalin for light microscopy including immunohistochemistry. Other specimens were used for additional studies-including polymerase chain reaction (PCR) for bacterial nucleic acids-or stored frozen. No complications were noted in any of the subjects. Tissue with identifiable synovium was obtained from 12 subjects and the immunohistochemical characteristics of these samples were studied. Because of technical problems, some specimens were not successfully stained with the immunohistochemical markers. Two biopsies could only be stained for HLA-DR and KP-1.

\section{Preparation of samples and immunohistochemical staining}

Unstained sections of the formalin fixed synovial tissue from paraffin blocks were deparaffinised through xylene immersions for three changes of two minutes each, followed by graded alcohol immersions to water and phosphate buffered saline solutions. Immunostaining was done using an automated immunostainer (Ventana-320, Tucson, Arizona, USA), according to the manufacturer's programme and recommendations. Antibodies used, source, and dilutions were as follows: CD3, Dako (Ao452; Carpinteria, California, USA) 1:100; CD4, Novacastra (NCL-cd4-1/f9; obtained from Vector, Burlingame, California, USA) 1:40; CD8 (cd8/144B), Dako (M7107) 1:50; KP-1-CD 68, Dako (M814) 1:200; L26, Dako 1:200, and HLADR, Dako (Mo746) 1:20. All assays used citrate buffer and low wattage microwaving for antigen retrieval.

\section{Microscopic analysis}

All the sections with a synovial lining layer were evaluated. Only nucleated cells with a distinct cytoplasmic or surface staining were counted. Positively staining cells were counted in all high power fields that contained synovial lining cells. A mean value per high power field was obtained. The size of high power field (hpf, $40 \times$ ) was calculated by using a stage micrometer (with 100 gradations of $0.01 \mathrm{~mm}$ each) and found to be $0.159 \mathrm{~mm}^{2}$, thus generating a conversion formula of cells $/ \mathrm{mm}^{2}=$ cells $/ \mathrm{hpf} \times 0.159^{-1}$. The results are expressed as positive cells $/ \mathrm{mm}^{2}$.

\section{Statistical analysis}

In addition to mean (SD), medians and ranges are given for the cell subpopulations. As a few subjects had palpable crepitus, low titre RF, or a raised ESR, numbers of the various cell subpopulations were compared between the subjects with and without retropatellar crepitus, and between those with a normal ESR and no RF and those with a raised ESR or positive RF, using a two sided Student $t$ test. As we undertook multiple comparisons, a Bonferroni adjustment was done and results were considered significant for a probability $(p)$ value of $<0.003(=0.05 / 15)$. Correlation analyses between age and cell subpopulations were done. For statistical analyses we used SPSS version 11.5 (SPSS Inc, Chicago, Illinois, USA).

\section{RESULTS}

\section{Subject characteristics}

Clinical and demographic features of subjects are summarised in table 1 . The study group consisted of seven women and five men with mean (SD) age of 37 (9) years (range 25 to 51 ). None of the subjects had a history of arthritis. A detailed physical examination revealed no joint swelling, warmth, redness, tenderness, or limitation of range of motion in any of the subjects. Mild retropatellar crepitus was noted in five subjects in the absence of knee effusion. $\mathrm{C}$ reactive protein was within normal limits for all subjects (normal range 0 to $0.8 \mathrm{mg} / \mathrm{dl}$ ). ANA was negative in all subjects (titre $<1: 80$ ). Two subjects were positive for rheumatoid factor at levels of 25 and $44 \mathrm{IU} / \mathrm{ml}$ (normal 0 to 20); however, no rheumatological disease was found and the ESR was normal. Two female subjects (different from those with positive rheumatoid factor), aged 35 and 51 years, had ESR values of 51 and $52 \mathrm{~mm} / \mathrm{h}$ respectively. Knee $x$ rays were normal in all subjects.

Serological testing was negative for salmonella, shigella, yersinia, campylobacter, and parvovirus B19. Two subjects had positive findings on PCR tests on synovial tissue for chlamydial DNA. These subjects were initially described in one of our previous reports. ${ }^{16}$ The first subject was a 30 year old African-American woman positive for both chlamydial 16S ribosomal RNA and major outer membrane protein (MOMP), each of which was confirmed by hybridisation. The second subject was a 51 year old African-American woman who was positive for $16 \mathrm{~S}$ ribosomal RNA with hybridisation, but had an inconclusive hybridisation for MOMP.

\section{Immunohistochemical findings}

A summary of the number of synovial specimens staining positive for the presence of each of the cell markers is provided in table 2 . We detected the presence of $\mathrm{CD} 3+\mathrm{T}$ lymphocytes in nine of 10 biopsies, and L26+ B lymphocytes in none of the biopsies. KPI+ macrophages and HLA-DR+ cells were found in 10 of 10 biopsies. Even after exclusion of patients with either abnormal laboratory values (raised ESR or low titre positive RF) or a positive chlamydial DNA, the distribution was similar: CD3+ T lymphocytes in five of six biopsies, L26+ B lymphocytes in none, KPl+ macrophages in five of five, and HLA-DR+ cells in five of five (table 2).

Table 1 Demographic and clinical characteristics of participating subjects

\begin{tabular}{ll}
\hline Variable & $\begin{array}{l}\text { Subjects } \\
(\mathbf{n}=12)\end{array}$ \\
\hline Mean age (mean (SD)) & $37(9)$ \\
Sex (M:F) & $5: 7$ \\
Race (white:black) & $5: 7$ \\
Retropatellar crepitus on physical examination & $5 / 12$ \\
Raised C reactive protein & $0 / 12$ \\
Raised ESR & $2 / 12^{*}$ \\
Positive rheumatoid factor & $2 / 12 \dagger$ \\
Positive antinuclear antibody & $0 / 12$ \\
\hline
\end{tabular}

*ESR values were 51 and $52 \mathrm{~mm} / \mathrm{h}$.

†RF titres were 25 and $44 \mathrm{IU} / \mathrm{ml}$ (normal $<20 \mathrm{IU} / \mathrm{ml}$ ).

$E S R$, erythrocyte sedimentation rate. 
Table 2 Distribution of various cells in synovial tissue of 12 healthy subjects

\begin{tabular}{|c|c|c|c|c|}
\hline & \multicolumn{2}{|l|}{ All subjects $(n=12)$} & \multicolumn{2}{|c|}{$\begin{array}{l}\text { Subjects with normal laboratory results and negative chlamydial } \\
\text { DNA }(n=7)\end{array}$} \\
\hline & $\begin{array}{l}\text { No of subjects with } \\
\text { respective cells }\end{array}$ & Cells $/ \mathrm{mm}^{2}$ & $\begin{array}{l}\text { No of subjects with } \\
\text { respective cells }\end{array}$ & Cells $/ \mathrm{mm}^{2}$ \\
\hline \multicolumn{5}{|l|}{ CD3+ $\mathrm{T}$ cells } \\
\hline Perivascular & $8 / 10$ & $31(41) ; 19(0$ to 136$)$ & $5 / 6$ & $36(50) ; 19$ (0 to 136$)$ \\
\hline Diffuse & $3 / 10$ & $3(7) ; 0$ (0 to 23$)$ & $1 / 6$ & $4(9) ; 0$ (0 to 23$)$ \\
\hline SLC & $0 / 10$ & $0 ; 0$ & $0 / 6$ & $0 ; 0$ \\
\hline Total (any location) & $9 / 10$ & $34(47) ; 19$ (0 to 158$)$ & $5 / 6$ & $39(59) ; 19$ (0 to 158$)$ \\
\hline \multicolumn{5}{|l|}{ CD4+ T cells } \\
\hline Perivascular & $3 / 7$ & $9(15) ; 0(0$ to 40$)$ & $1 / 4$ & $3(5) ; 0(0$ to 10$)$ \\
\hline Diffuse & $1 / 7$ & $1(2) ; 0$ (0 to 5$)$ & $0 / 4$ & $0 ; 0$ \\
\hline SLC & $0 / 7$ & $0 ; 0$ & $0 / 4$ & $0 ; 0$ \\
\hline Total (any location) & $3 / 7$ & $10(15) ; 0(0$ to 40$)$ & $1 / 4$ & $3(5) ; 0$ (0 to 11$)$ \\
\hline \multicolumn{5}{|l|}{ CD8+ T cells } \\
\hline Perivascular & $5 / 8$ & $10(14) ; 6(0$ to 41$)$ & $3 / 5$ & $8(8) ; 9$ (0 to 19$)$ \\
\hline Diffuse & $2 / 8$ & $0(1) ; 0(0$ to 2$)$ & $0 / 5$ & $0 ; 0$ \\
\hline SLC & $0 / 8$ & $0 ; 0$ & $0 / 5$ & $0 ; 0$ \\
\hline Total (any location) & $6 / 8$ & $11(14) ; 7(0$ to 41$)$ & $3 / 5$ & $8(8) ; 9$ (0 to 19$)$ \\
\hline \multicolumn{5}{|l|}{ L26+ B cells } \\
\hline Perivascular & $0 / 9$ & $0 ; 0$ & $0 / 5$ & $0 ; 0$ \\
\hline Diffuse & $0 / 9$ & $0 ; 0$ & $0 / 5$ & $0 ; 0$ \\
\hline SLC & $0 / 9$ & $0 ; 0$ & $0 / 5$ & $0 ; 0$ \\
\hline \multicolumn{5}{|l|}{ Kpl+ macrophages } \\
\hline Perivascular & $2 / 10$ & $1(3) ; 0$ (0 to 8$)$ & $0 / 5$ & $0 ; 0$ \\
\hline Diffuse & $7 / 10$ & $9(8) ; 11$ (0 to 23$)$ & $4 / 5$ & $10(8) ; 8(0$ to 21$)$ \\
\hline SLC & $10 / 10$ & 41 (22); 44 (7 to 75 ) & $5 / 5$ & 28 (22); 23 (7 to 59) \\
\hline Total (any location) & $10 / 10$ & $52(22) ; 52$ (0 to 83$)$ & $5 / 5$ & $39(20) ; 28$ (23 to 72$)$ \\
\hline \multicolumn{5}{|l|}{ HLA-DR+ cells } \\
\hline Perivascular & $6 / 10$ & $6(10) ; 1(0$ to 27$)$ & $3 / 5$ & $6(12) ; 1$ (0 to 27$)$ \\
\hline Diffuse & $8 / 10$ & $19(28) ; 10$ (0 to 95$)$ & $4 / 5$ & $29(38) ; 21(0$ to 95$)$ \\
\hline SLC & $10 / 10$ & $55(20) ; 52$ (31 to 104$)$ & $5 / 5$ & 60 (34); 55 (31 to 104) \\
\hline Total (any location) & $10 / 10$ & 80 (35); 75 (0 to 144 ) & $5 / 5$ & $94(44) ; 103$ (33 to 144$)$ \\
\hline
\end{tabular}

The pattern of distribution of $\mathrm{CD} 3+\mathrm{T}$ lymphocytes was perivascular in eight of 10 biopsies, diffuse in three of 10, and mixed in two of 10 (fig 1A). CD4+ cells (helper/inducer T lymphocytes) were seen in three of seven stained biopsies and CD8+ cells in six of eight biopsies. With the exception of two subjects who had only a very few CD8+ cells and no CD4+ cells, the rest had a mixed T cell infiltrate with a mean CD4:CD8 ratio of approximately 1.1:1. A summary of mean numbers of positive cells for each cell marker is provided in table 2. There was a wide range in the mean number of CD3, CD4, and CD8 positive cells among the subjects. Most of these cells were found in a perivascular distribution, although a few were seen diffusely. No L26+ B lymphocytes were seen in any of the synovial specimens (table 2). The observations were similar even after exclusion of the five patients with either abnormal laboratory tests or positive chlamydial DNA (table 2).

$\mathrm{Kpl}+$ macrophages were seen in all the stained biopsies (10 of 10) and were found predominantly in the surface lining cells (fig 1B). Two of 10 subjects had a small number of macrophages in the perivascular areas and seven of 10 had macrophages diffusely in the subsynovium. There were more $\mathrm{Kpl}+$ macrophages in the surface lining than in a perivascular or diffuse distribution. HLA-DR+ cells were seen in all the stained synovial biopsies (10 of 10) (table 2). HLA-DR positive cells were seen in the surface lining in 10 of 10 biopsies, diffusely in eight of 10, and perivascularly in six of 10. The majority of HLA-DR+ cells were in the surface lining and in a diffuse distribution, with small numbers in a perivascular distribution (fig $1 C$ and $1 \mathrm{D}$; table 2). In most cases, we detected a slightly larger number of HLA-DR+ cells than Kpl positive macrophages (table 2). This was true for all three distributions of these cells, namely surface lining cells, perivascularly, and diffusely. The numbers of Kpl+ and HLA$\mathrm{DR}+$ cells ranged from a few to many. An example of such a variation in numbers of HLA-DR+ cells is shown in fig $\mathrm{IC}$ and 1D. After exclusion of subjects with a raised ESR, low titre positive RF, or chlamydial DNA, our observations of both the distribution and the number of various cell populations were similar to those described above (table 2).

Comparison of subjects with retropatellar crepitus and those without crepitus showed no significant differences in the cell subpopulations (table 3 ). There were suggestions of slightly greater numbers of macrophages, CD4+ T lymphocytes, and CD8+T lymphocytes in subjects with either an abnormal ESR or presence of RF compared with those with a normal ESR and no RF, but the differences were not statistically significant in this small sample (table 3 ). There was no correlation between numbers of various cell subpopulations and the age of the subject (data not shown). With the exception of a high ESR of $52 \mathrm{~mm} / \mathrm{h}$ in the second patient, no other abnormalities were noted on history, examination, or laboratory results in either subject with evidence of chlamydial DNA in the synovial tissue. On comparing two subjects with PCR evidence of chlamydia DNA with the rest of the group, no significant differences in numbers of $\mathrm{CD} 3+, \mathrm{CD} 4+$, or CD8+ T cells, Kp- $1+$ macrophages, or HLA-DR+ cells were found (data not shown). Our inability to detect differences between the groups may reflect type II error resulting from the small sample size. Although some cell populations (CD4+ and CD8+ T cells) tended to be more numerous in patients with PCR evidence of chlamydia 

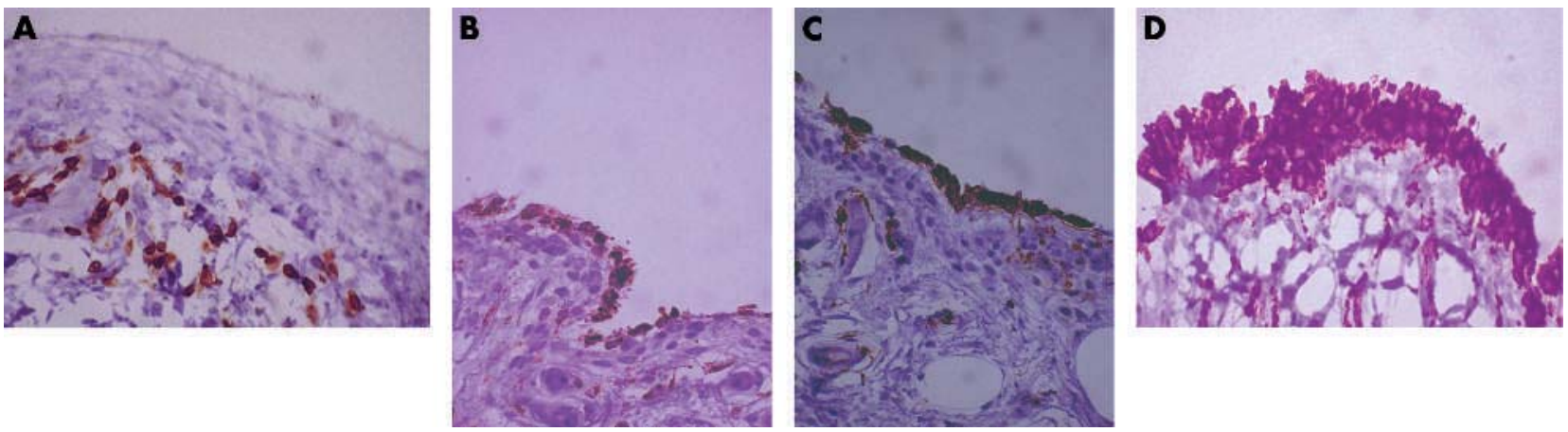

Figure 1 (A) Synovial tissue from subject 1 (no retropatellar crepitus, normal laboratory values, chlamydia negative) showing the presence of few CD3+ T cells. (B) Significant numbers of Kpl+ macrophages seen in surface lining cells and scattered cells in a diffuse distribution in the synovium of subject 2 (no retropatellar crepitus, low positive rheumatoid factor, chlamydia negative). (C) HLA-DR+ cells in the surface lining layer with a few scattered diffusely in superficial parts of synovium of subject 2. (D) Significant numbers of HLA-DR+ cells in the lining layer and in other distributions in subject 3 (no retropatellar crepitus, low positive rheumatoid factor, chlamydia negative), showing the variation in numbers of positive cells between subjects. Only nucleated cells with a distinct cytoplasmic or surface staining were counted.

DNA, even after excluding these two patients impressive numbers of cells were seen in the synovium in the rest of the subjects, as follows (mean (SD)): CD3+, 31 (49) cells $/ \mathrm{mm}^{2}$; $\mathrm{Kpl}+, 49(23) / \mathrm{mm}^{2} ; \mathrm{HLA}-\mathrm{DR}+, 84(37) / \mathrm{mm}^{2} ; \mathrm{CD} 4+, 5(8) /$ $\mathrm{mm}^{2}$; and CD8+, $6(7) / \mathrm{mm}^{2}$. Similarly, even after exclusion of subjects with crepitus or abnormal ESR/RF, large numbers of CD3+, CD4+, CD8+, Kpl+, and HLA-DR+ cells were seen in synovium of the rest of the subjects (table 3 )

\section{DISCUSSION}

The results of this study using immunohistochemical staining showed a variety of immune cells in apparently normal synovium from healthy participants. Significant numbers of T lymphocytes (both CD4+ and CD8+), macrophages, and HLADR+ cells were found in the synovial biopsy specimens. On the other hand, B lymphocytes were not seen in any of our specimens. T lymphocytes were found predominantly in a perivascular distribution, macrophages in the surface lining layer, and HLA-DR positive cells in the surface lining layer and diffusely. A trend towards slightly greater number of macrophages and lymphocytes in subjects with abnormal laboratory tests or positive chlamydial DNA was noted, but this was not statistically significant in this small sample.

Some of our study methods and results differ from most of the previously reported studies. Instead of enrolling patients with traumatic knee injuries, we attempted to study healthy "truly" normal subjects who agreed to undergo needle knee biopsies. Compared with the small numbers of T lymphocytes (qualitatively "few") reported in previous studies, ${ }^{8}{ }^{15}$ we found a wide range of 0 to 25 cells per high power field ( 0 to 158 cells $/ \mathrm{mm}^{2}$; mean (SD), 33 (47) cells $/ \mathrm{mm}^{2}$ ). Even after excluding the two patients with PCR evidence of chlamydial
DNA and abnormal laboratory findings, a wide range in numbers of $\mathrm{CD} 3+\mathrm{T}$ cells was seen in the synovium of our subjects (0 to 158 cells $/ \mathrm{mm}^{2}$; mean (SD), 39 (59) cells $/ \mathrm{mm}^{2}$ ). It is difficult to compare this with the previous studies, as the exact number of cells was only mentioned in one study ( 3 cells $/ \mathrm{mm}^{2}$ ). ${ }^{15}$ We also found a slightly higher percentage of biopsies with perivascular T lymphocytes in our study (90\%), compared with $70 \%$ in an earlier report. ${ }^{12} \mathrm{~B}$ lymphocytes were conspicuously absent in all our synovial specimens, though they were reported to be occasionally present in the earlier report of synovium from four normal healthy subjects. ${ }^{8}$ We also detected a few biopsies with perivascular accumulation of Kp-l and HLA-DR positive cells, which, to our best knowledge, has not been reported before. Finally, we report the exact number of cells per high power field and per $\mathrm{mm}^{2}$, which were calculated as an average of the total number of cells counted in all the sections of the slides.

Some of the findings in our study confirm earlier observations. As in the earlier study of normal synovium, we confirmed that perivascular $\mathrm{T}$ lymphocytes, HLA-DR+ cells in synovial lining, and a mixture of both $\mathrm{T}$ helper and $\mathrm{T}$ suppressor/cytotoxic cells can be seen in apparently normal joints. $^{8}$

Similar to studies of synovium in patients undergoing limb amputation for sarcoma ${ }^{15}$ and in traumatic knee injuries, ${ }^{16}$ HLA-DR positive cells were more frequent than Kpl positive macrophages. ${ }^{15}$ Immuno-electron microscopy of normal synovium has confirmed the presence of HLA-DR on the surface of both type A and type B synovial lining cells, ${ }^{18}$ thus establishing that even normal synovium contains antigen presenting cells of both macrophage and non-macrophage origin. We noted the presence of HLA-DR positive cells in all

Table 3 Comparison of cell subpopulations between various patient groups

\begin{tabular}{llllll}
\hline & CD3+ cells & CD4+ cells & CD8+ cells & Kp1+ cells & HLA-DR+ cells \\
\hline All subjects $(n=12)$ & $34(47)$ & $10(15)$ & $11(14)$ & $52(22)$ & $80(35)$ \\
No crepitus $(n=5)$ & $44(60)$ & $15(19)$ & $12(17)$ & $55(25)$ & $76(38)$ \\
Crepitus $(n=7)$ & $17(12)$ & $4(6)$ & $9(9)$ & $47(19)$ & $85(34)$ \\
$p$ Value & 0.39 & 0.38 & 0.83 & 0.61 & 0.70 \\
Normal ESR and RF $(n=8)$ & $39(59)$ & $3(5)$ & $7(8)$ & $41(20)$ & $87(43)$ \\
Abnormal ESR or RF $(n=4)$ & $25(28)$ & $20(20)$ & $16(22)$ & $68(15)$ & $69(15)$ \\
$p$ Value* & 0.67 & 0.15 & 0.58 & 0.054 & 0.45 \\
\hline
\end{tabular}

Values are $\mathrm{n} / \mathrm{mm}^{2}$ (mean (SD)).

*Exact $p$ values; all other numbers are rounded to the nearest digit.

ESR, erythrocyte sedimentation rate; RF, rheumatoid factor. 
locations-that is, surface lining (predominantly), diffusely, and perivascularly. The subject with an extremely large number of HLA-DR+ cells had no abnormality on laboratory or physical examination.

The most remarkable observation in our study was the strikingly wide range of "abnormalities" in these "normal" synovial biopsies obtained from healthy subjects with no disease. A wide range in the number and variability in distribution of $\mathrm{T}$ lymphocytes, macrophages, and HLA-DR+ cells was seen. This remained true irrespective of whether the two patients with PCR evidence of chlamydial DNA, or the four subjects with abnormal laboratory tests, or both groups (five subjects), were included or excluded from analyses. In fact, a similar observation of significant variation in numbers of HLA-DR+ cells was made in two subjects with traumatised but otherwise normal knees. ${ }^{16}$ Some biopsies with a large number of macrophages and T lymphocytes may even be indistinguishable from the synovium from patients with early rheumatoid synovitis. ${ }^{22} 23$

So, despite the presence of T lymphocytes and HLA-DR positive macrophages (in the lining), what protects normal synovium from progressing to symptomatic disease? It seems that the presence of these cells is necessary, but not sufficient for the development of overt inflammatory arthritis. We believe that the finding of $\mathrm{T}$ cells and HLA-DR positive macrophages in synovium from subjects without signs and symptoms of joint inflammation does reflect a reaction to unknown stimuli that does not usually progress to overt disease. We showed previously that nucleic acids from an infectious agent, Chlamydia trachomatis, can be found in normal joints. ${ }^{19}$ These two subjects with chlamydial DNA from our previous report ${ }^{19}$ had slightly larger numbers of CD4+ and CD8+ T cells than the rest of the group (statistically non-significant), but no history of joint symptoms. Although the differences in cell subpopulations are not statistically significant, these results are vulnerable to type 2 error (that is, no differences are detected when differences truly exist) owing to a small sample size. Perhaps genetic susceptibility plays a key role in determining whether the inflammatory changes seen resolve or progress to clinical disease. As we have no sequential studies or clinical follow up, we cannot exclude the possibility that one or more of these subjects will develop overt synovitis. Although statistically non-significant, the finding of slightly larger numbers of $\mathrm{Kp}-\mathrm{l}+$ macrophages and CD4+ cells in healthy subjects with abnormal ESR or RF needs further study.

A major difference in the synovial findings in our study and the studies of RA synovium is the absence of B cells in normal synovium and their presence in chronic rheumatoid arthritis. ${ }^{1324}$ Interestingly, at least some B cells were seen in synovium from asymptomatic joints in patients with rheumatoid arthritis, both in early ${ }^{22}$ and late disease. ${ }^{25}$ It is possible that $\mathrm{B}$ cells may play an important role in the initiation of immune mediated damage to the synovium.

There are certain limitations to our study. Owing to the small sample size, it was vulnerable to type II error. Larger studies of immunohistochemistry of normal synovium are needed to explore the relation of cell subpopulations to age and the presence of abnormalities on clinical examination and laboratory findings. An absence of such a correlation in our study may either be a true finding or reflect the small sample size. Even though multiple synovial samples obtained with a needle biopsy provided suitable tissue for detailed immunohistological examination, ${ }^{26}{ }^{27}$ variation in the histological features of diseased joints has been noted..$^{28}$ Although no previous study has examined whether there are variations in histological features within normal joints, we observed a considerable variation in the numbers of various cell populations between synovial pieces and even in different areas of the same synovial piece. We did not exclude subjects who had mild crepitus on patello-femoral grinding. It seems likely that these and even others could have had some mild but otherwise undetected osteoarthritis despite the absence of symptoms and their normal knee $x$ rays. A clinical follow up of the subjects could provide an interesting clinical correlation, but because of the nature of the contract with the participating subjects, we were unable to contact them for a follow up study. We did not carry out immunohistochemical staining for cytokines, which may have provided interesting information.

We believe that this is first report of immunohistochemical features of knee synovium in such a large number of healthy, normal subjects. As we used a quantitative technique, comparisons can easily be made in future studies. Our study also highlights the difficulty of being certain what is truly "normal" in a population, as our careful scrutiny detected the few clinical and laboratory changes noted in these asymptomatic subjects. Other normal controls will need to be characterised at least as well.

\section{Conclusions}

Synovial biopsies from apparently normal subjects showed a wide range of abnormalities by immunohistochemical methods, including the presence of T lymphocytes, macrophages, and HLA-DR positive cells, but no B lymphocytes. More studies of normal synovium are needed to understand the importance and implications of the presence of these cells in health, and their relation to findings in disease.

\section{ACKNOWLEDGEMENTS}

We thank Mariana Crane, our nurse, and other staff members at outpatient clinics and the pathology laboratory at NIAMS, National Institutes of Health, Bethesda, Maryland, for recruiting the subjects and processing the synovial specimens. We also thank Dr Maren Mahowald, University of Minnesota, for her critical review of the manuscript. Grant support was from a postdoctoral fellowship grant (No 38091M) of the Arthritis Foundation, Eastern Missouri Chapter, St Louis, Missouri, USA.

\section{Authors' affiliations}

J A Singh, Minneapolis VA Medical Center and University of Minnesota, Minneapolis, Minnesota, USA

T Arayssi, American University of Beirut; Beirut, Lebanon

P Duray, National Institute of Arthritis and Musculoskeletal Diseases, Bethesda, Maryland, USA

H R Schumacher, Philadelphia VA Medical Center and University of Pennsylvania, Philadelphia, Pennsylvania, USA

\section{REFERENCES}

1 Barland $P$, Novikoff $A B$, Hamerman D. Electron microscopy of the human synovial membrane. J Cell Biol 1962;14:207-20.

2 Castor CW. The microscopic structure of normal human synovial tissue. Arthritis Rheum 1960;3:140-51.

3 Coulter WH. The characteristics of human synovial tissue as seen with the electron microscope. Arthritis Rheum 1962;5:70-80.

4 Davies DV, Palfrey AJ. The fine structure of normal and rheumatoid synovial membrane. Mod Trends Rheumatol 1971;2:1-20.

5 Krey PR, Cohen AS, Smith CB, Finland M. The human fetal synovium. Histology, fine structure and changes in organ culture. Arthritis Rheum $1971 ; 14: 319-41$.

6 Lever JD, Ford EHR. Histological, histochemical and electron microscopic observations on synovial membrane. Anat Rec 1958;132:525-39.

7 Wynne-Roberts CR, Anderson CH. Light- and electron-microscopic studies of normal juvenile human synovium. Semin Arthritis Rheum 1978;7:279-86.

8 Lindblad S, Hedfors E. The synovial membrane of healthy individuals immunohistochemical overlap with synovitis. Clin Exp Immunol 1987;69:41-7

9 Klareskog L, Forsum U, Malmnas Tjernlund U, Kabelitz D, Wigren A. Appearance of anti-HLA-DR-reactive cells in normal and rheumatoid synovial tissue. Scand J Immunol 1981;14:183-92.

10 Duke O, Panayi GS, Janossy G, Poulter LW. An immunohistological analysis of lymphocyte subpopulations and their microenvironment in the synovial membranes of patients with rheumatoid arthritis using monoclonal antibodies. Clin Exp Immunol 1982;49:22-30. 
11 Burmester GR, Locher P, Koch B, Winchester RJ, Dimitriu-Bona A, Kalden JR. The tissue architecture of synovial membranes in inflammatory and noninflammatory joint diseases. I. The localization of the major synovial cell populations as detected by monoclonal reagents directed towards la and monocyte-macrophage antigens. Rheumatol Int 1983;3:173-81.

12 Poulter LW, Duke O, Hobbs S, Janossy G, Panayi G. Histochemical discrimination of HLA-DR positive cell populations in the normal and arthritic synovial lining. Clin Exp Immunol 1982;48:381-8

13 Young CL, Adamson TC, Vaughan JH, Fox RI. Immunohistologic characterization of synovial membrane lymphocytes in rheumatoid arthritis. Arthritis Rheum 1984;27:32-9.

14 Husby G, Williams RC. Immunohistochemical studies of interleukin-2 and gamma-interferon in rheumatoid arthritis. Arthritis Rheum 1985;28:174-81.

15 Allard SA, Bayliss MT, Maini RN. The synovium-cartilage junction of the normal human knee. Implications for joint destruction and repair. Arthritis Rheum 1990;33:1170-9.

16 Athanasou NA, Quinn J, Heryet A, Puddle B, Woods CG, McGee JO, et al. The immunohistology of synovial lining cells in normal and inflamed synovium. J Pathol 1988;155:133-42.

17 Klareskog L, Forsum U, Kabelitz D, Ploen L, Sundstrom C, Nilsson K, et al. Immune functions of human synovial cells. Phenotypic and T cell regulatory properties of macrophage-like cells that express HLA-DR. Arthritis Rheum 1982;25:488-501.

18 Shiozawa S, Shiozawa K, Fujita T. Presence of HLA-DR antigen on synovial type $A$ and $B$ cells: an immunoelectron microscopic study in rheumatoid arthritis, osteoarthritis and normal traumatic joints. Immunology 1983;50:587-94.

19 Schumacher HR, Arayssi T, Crane M, Lee J, Gerard H, Hudson AP, et al. Chlamydia trachomatis nucleic acids can be found in the synovium of some asymptomatic subjects. Arthritis Rheum 1999;42:1281-4.
20 Parker RH, Pearson CM. A simplified synovial biopsy needle. Arthritis Rheum 1963;6:172-6.

21 Schumacher HR, Kulka JP. Needle biopsy of the synovial membrane experience with the Parker-Pearson technic. NEngl J Med 1972;286:416-19.

22 Pando JA, Duray P, Yarboro C, Gourley MF, Klippel JH, Schumacher HR. Synovitis occurs in some clinically normal and asymptomatic joints in patients with early arthritis. J Rheumatol 2000;27:1848-54

23 Konttinen YT, Bergroth V, Nordstrom D, Koota K, Skrifvars B, Hagman G, et al. Cellular immunohistopathology of acute, subacute, and chronic synovitis in rheumatoid arthritis. Ann Rheum Dis 1985;44:549-55.

24 Rooney M, Whelan A, Feighery C, Bresnihan B. The immunohistologic features of synovitis, disease activity and in vitro $\lg M$ rheumatoid factor synthesis by blood mononuclear cells in rheumatoid arthritis. J Rheumatol 1989; 16:459-67.

25 Soden M, Rooney M, Cullen A, Whelan A, Feighery C, Bresnihan B. Immunohistological features in the synovium obtained from clinically uninvolved knee joints of patients with rheumatoid arthritis. $\mathrm{Br} J$ Rheumatol 1989;28:287-92

26 Rooney M, Condell D, Quinlan W, Daly L, Whelan A, Feighery C, et al. Analysis of the histologic variation of synovitis in rheumatoid arthritis. Arthritis Rheum 1988;31:956-63.

27 Youssef PP, Kraan M, Breedveld F, Bresnihan B, Cassidy N, Cunnane G, et al. Quantitative microscopic analysis of inflammation in rheumatoid arthritis synovial membrane samples selected at arthroscopy compared with samples obtained blindly by needle biopsy. Arthritis Rheum 1998;41:663-9.

28 Hutton CW, Hinton C, Dieppe PA. Intra-articular variation of synovial changes in knee arthritis: biopsy study comparing changes in patellofemoral synovium and the medial tibiofemoral synovium. $\mathrm{Br} J$ Rheumatol 1987;26:5-8. 